\title{
Lymphoepithelial Carcinoma of the Lower Lip: Report of a Case
}

\author{
Melis GULTEKIN ${ }^{1}$, Sezin Y. SARI ${ }^{1}$, Omer GUNHAN ${ }^{2}$, Sefik HOSAL ${ }^{3}$, \\ Mustafa CENGIZ1 ${ }^{\text {, Murat GURKAYNAK }}{ }^{1}$ \\ ${ }^{1}$ Hacettepe University Faculty of Medicine, Department of Radiation Oncology \\ ${ }^{2}$ Gülhane Military Medical Academy and Faculty of Medicine, Department of Pathology \\ ${ }^{3}$ Hacettepe University Faculty of Medicine, Department of Ear, Nose, and Throat Surgery, Ankara, TURKEY
}

To the editor,

A 41-year-old male presented in July 2010 with a nonhealing wound on the lower lip. The physical examination revealed an ulcerated lesion situated in the middle of the lower lip, measuring $1 \mathrm{~cm}$ in diameter. There were no palpable cervical lymph nodes. The excisional biopsy revealed undifferentiated tumor, and was consistent with lymphoepithelial carcinoma (LEC). Histologically, the tumor consisted of atypical epithelial cells with large vesicular nuclei and prominent nucleoli and showed a syncytial pattern (Figure 1A). There were lymphocytes and plasma cells between the tumor cells. Cytokeratin and epithelial membrane antigen were demonstrated inside the tumor cells by immunohistochemical staining, while staining for HMB-45, melan-A and leukocyte common antigen was negative (Figure 1B). The immunohistochemical stains for EBV and polymerase chain reaction $(\mathrm{PCR})$ were also negative. Three days after the initial excision, partial lower lip resection and bilateral selective neck dissection (level I-II) were performed. There was no residual tumor. The surgical margins were negative. Neck dissection revealed only one metastatic lymph node in the left level $1 \mathrm{~B}$ region, and it was negative for extracapsular extension. Resection of 11 additional lymph nodes was reactive. TNM classification was T1N1M0 (stage III). When he was referred to our hospital, positron emission tomography/computed tomography (PET/CT) scan was applied, and there was no active disease or distant metastasis. This case was reviewed in the multidisciplinary Ear-Nose-Throat Tumor Board, and concurrent chemoradiotherapy (CRT) was chosen as the best adjuvant treatment. He was treated with adjuvant radiotherapy (RT) to the primary site to a total dose of $60 \mathrm{~Gy}$ at $1.8 \mathrm{~Gy}$ per fraction once a day with a $6 \mathrm{MV}$ linear accelerator. After excluding the spinal cord at $45 \mathrm{~Gy}$, we completed the right upper neck to $54 \mathrm{~Gy}$ and left upper neck to $56 \mathrm{~Gy}$ with $9 \mathrm{MeV}$ electrons, simultaneously. Elective nodal irradiation to the lower neck bilaterally was not applied. He was given 35 $\mathrm{mg} / \mathrm{m}^{2}$ concurrent cisplatinum weekly for seven weeks. He complained about loss of taste and xerostomia in the second week of the treatment. In the third week, oral mucositis was seen, and mouthwash with both nystatin and benzydamine twice a day was recommended. After one week, his complaints decreased. He then started to complain about minimal bleeding in the lower gingiva. At three years follow-up, the patient was alive with no evidence of disease. Lymphoepithelioma is an undifferentiated non-keratinizing carcinoma associated with a prominent lymphoid stroma, and it most commonly arises in the nasopharynx. ${ }^{1}$ Uncommon tumors with similar histology arising from other sites are defined as 'lymphoepithelioma-like carcinoma' (LELC) or 'lymphoepithelial carcinoma' (LEC). These areas include the salivary glands, trachea, thymus, larynx, Waldeyer's ring, oral cavity, lip, hypopharynx, uterine cervix, vagina, skin, lung, and gastrointestinal tract. ${ }^{1}$ There is a well-known association between Epstein-Barr virus (EBV) and lymphoepithelioma, but the relationship in other localizations is not that clear and shows a strong racial variation. ${ }^{1}$ 


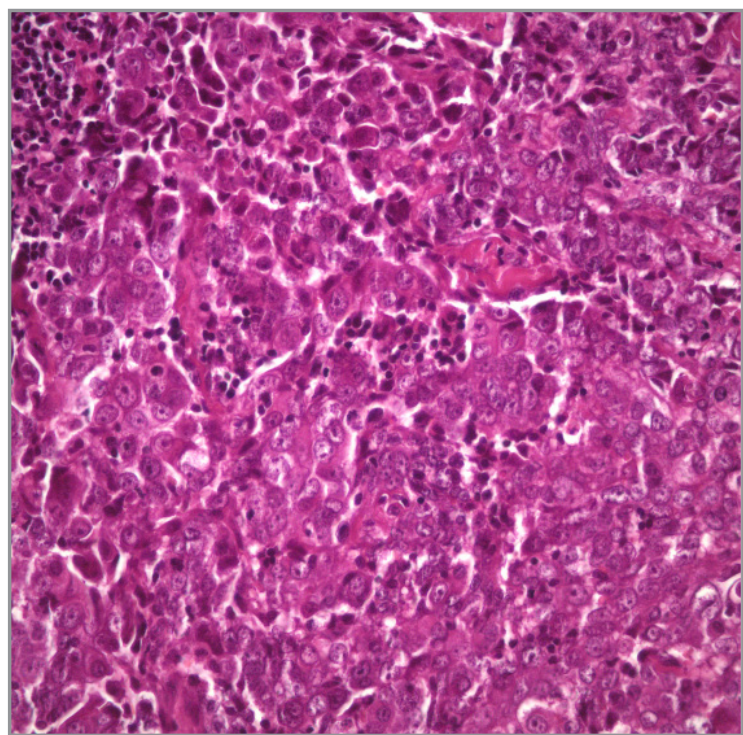

Figure 1A. Immunohistochemical staining is positive for cy-

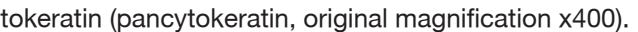

There is also a strong ethnic variation for the EBV relationship. ${ }^{2}$ In Turkey, there is a high incidence of nasopharyngeal carcinoma, and it is usually linked to EBV infection. ${ }^{3}$ However, no EBV relationship was observed in our patient, suggesting that some additional factors, such as genetic and environmental, also affect the tumor development, and this process is very complex.

The natural course of lymphoepithelioma is early regional lymph node and distant metastases, and these factors are important considerations for prognosis. ${ }^{4}$ Histologically, the tumor consists of atypical epithelial-derived cells that have pale cytoplasm, prominent stroma, large-round vesicular nucleus, and prominent nucleoli. ${ }^{1}$ There is no keratinization, necrosis or mucus production. ${ }^{5}$ The cells show no differentiation, and therefore they resemble melanoma or lymphoma cells. ${ }^{5}$ The tumor cells are surrounded by an extensive number of lymphocytes and plasma cells. ${ }^{1}$ Immunohistochemical stains for keratin and epithelial membrane antigen are positive. ${ }^{6}$

These tumors are highly radiosensitive, with high rates of locoregional control. ${ }^{1}$ Lymphoepithelioma was first described by Schmincke ${ }^{7}$, who reported that patients receiving RT had better prognosis even in advanced disease. Therefore, RT can be used as the primary treatment in head and neck LEC. ${ }^{4}$ A multi-

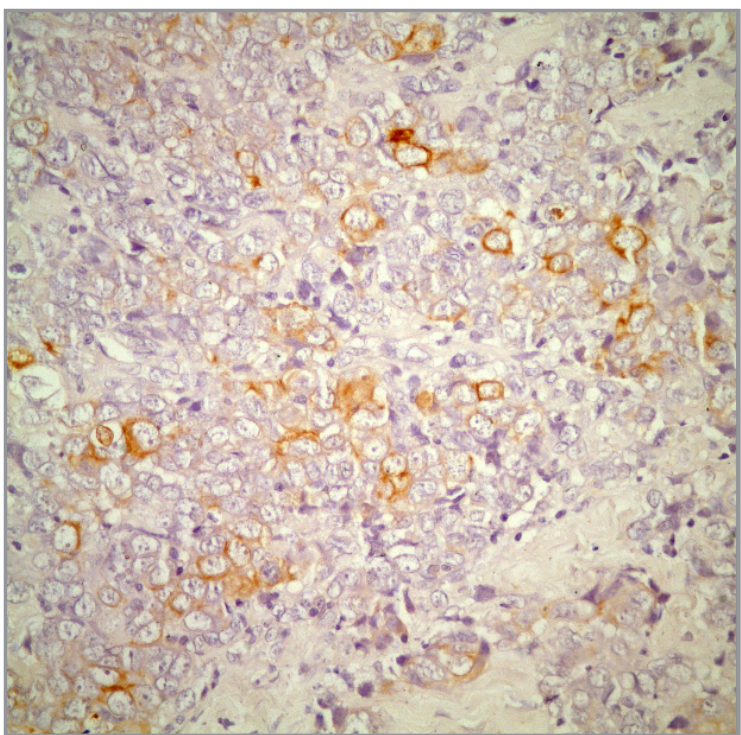

Figure 1B. The tumor is composed of atypical epithelial cells showing a syncytial pattern bounded by reactive lymphocytes and plasma cells. Tumor cells have large vesicular nuclei and prominent nucleoli (hematoxylin and eosin, original magnification $\times 400)$.

modality approach is generally recommended; surgery must be the first choice, if possible, regardless of localization..$^{5}$ In the literature, higher survival rates are noted for LEC of the oral cavity. Dubey et al. ${ }^{4}$ reported a $94 \%$ local control rate in LELCs in the head and neck region with RT. The five-year overall survival and disease-specific survival were found as $39 \%$ and $59 \%$, respectively. We treated our patient with LEC of the lower lip with adjuvant CRT after surgery. We did not experience any serious complications during the treatment, but longer follow-up is needed to determine the outcome.

LEC appears to be an uncommon tumor type of lip carcinoma. It accounted for about $1 \%$ of all lip cancers in a retrospective study. ${ }^{8}$ To the best of our knowledge, there is only one case report with LEC of the lip in the English literature. ${ }^{2}$ This patient had a non-healing lesion of the lower lip, and was initially diagnosed as 'actinic cheilosis'. Surgical excision was performed, and the pathology specimen revealed LEC. No adjuvant therapy was added. He was followed for 20 months without any signs of disease, but died of a heart attack. They concluded that surgery alone was effective in LEC of the lip. The immunohistochemistry and PCR were negative for EBV, and the authors concluded that EBV does not play a role in LEC of the lip. They added that LEC of the lip resembles the LELC of the skin, in which derivation 


\section{International Journal of Hematology and $\mathrm{Oncology}$}

from the skin integument has been described and EBV studies have been consistently negative, but not the other oral cavity LECs. ${ }^{9}$

In conclusion, owing to the rarity of this tumor, it is difficult to determine which treatment modality is superior. Literature data support the use of a combined modality approach. The treatment choice should be decided considering the clinical stage of the tumor. It seems that the main choice of treatment for LEC of the head and neck region is surgery. Adjuvant CRT should be added when there are factors indicating a high risk for recurrence. Elective neck radiotherapy is recommended for patients with head and neck LELC.

\section{REFERENCES}

1. Lee J, Lee SA, Kim H, et al. Lymphoepithelioma-like carcinoma in the trachea: report of a case. Surg Today 37: 584-586, 2007.

2. Mahomed F, Grayson W. A rare case of lymphoepithelial carcinoma of the lip. Oral Surg Oral Med Oral Pathol Oral Radiol Endod 105: 49-52, 2008.

3. Ozyar E, Gultekin M, Alp A, et al. Use of plasma Epstein-Barr virus DNA monitoring as a tumor marker in follow-up of patients with nasopharyngeal carcinoma: preliminary results and report of two cases. Int J Biol Markers 22: 194-199, 2007.

4. Dubey P, Ha CS, Ang KK, et al. Nonnasopharyngeal lymphoepithelioma of the head and neck. Cancer 82: 1556-1562, 1998.
5. Anqulo-Pernett F, Smythe WR. Primary lymphoepithelioma of the esophagus. Ann Thorac Surg 76: 603-605, 2003.

6. Shibata D, Tokunaga M, Uemura Y,et al. Association of Epstein-Barr virus with undifferentiated gastric carcinomas with intense lymphoid infiltration: lymphoepithelioma-like carcinoma. Am J Pathol 139: 469-474, 1991.

7. Schmincke A. Über Lymphoepitheliale Geschwulste. Pathol Anat 68: 161-170, 1921.

8. Luna-Ortiz K, Güemes-Meza A, Villavicencio-Valencia V, Mosqueda-Taylor A. Lip cancer experience in Mexico. Oral Oncol 40: 992-999, 2004.

9. Lind AC, Breer WA, Wick MR. Lymphoepithelioma-like carcinoma of the skin with apparent origin in the epidermis - a pattern or an entity? A case report. Cancer 85: 884-890, 1999.

\section{Correspondence}

Dr. Melis GÜLTEKIN

Hacettepe Üniversitesi

Radyasyon Onkolojisi Anabilim Dalı

06100 Sinhiye,

ANKARA / TURKEY

Tel: (+90.312) 3052900

Fax: (+90.312) 3092914

e-mail: melisgultekin@hacettepe.edu.tr 